\title{
BARIATRIC AND METABOLIC SURGERY REVIEW Can medical therapy mimic the clinical efficacy or physiological effects of bariatric surgery?
}

\author{
AD Miras ${ }^{1}$ and CW le Roux ${ }^{2}$
}

The number of bariatric surgical procedures performed has increased dramatically. This review discusses the clinical and physiological changes, and in particular, the mechanisms behind weight loss and glycaemic improvements, observed following the gastric bypass, sleeve gastrectomy and gastric banding bariatric procedures. The review then examines how close we are to mimicking the clinical or physiological effects of surgery through less invasive and safer modern interventions that are currently available for clinical use. These include dietary interventions, orlistat, lorcaserin, phentermine/topiramate, glucagon-like peptide-1 receptor agonists, dipeptidyl peptidase-4 inhibitors, pramlintide, dapagliflozin, the duodenal-jejunal bypass liner, gastric pacemakers and gastric balloons. We conclude that, based on the most recent trials, we cannot fully mimic the clinical or physiological effects of surgery; however, we are getting closer. A 'medical bypass' may not be as far in the future as we previously thought, as the physician's armamentarium against obesity and type 2 diabetes has recently got stronger through the use of specific dietary modifications, novel medical devices and pharmacotherapy. Novel therapeutic targets include not only appetite but also taste/food preferences, energy expenditure, gut microbiota, bile acid signalling, inflammation, preservation of $\beta$-cell function and hepatic glucose output, among others. Although there are no magic bullets, an integrated multimodal approach may yield success. Non-surgical interventions that mimic the metabolic benefits of bariatric surgery, with a reduced morbidity and mortality burden, remain tenable alternatives for patients and health-care professionals.

International Journal of Obesity (2014) 38, 325-333; doi:10.1038/ijo.2013.205

Keywords: medical bypass; gut hormones; pharmacotherapy; lifestyle intervention; devices

\section{INTRODUCTION}

Obesity is an increasingly prevalent worldwide health problem. Approximately one-third of US adults are obese, and obesity rates have increased dramatically in the past 20 years. The health consequences of obesity are numerous, with attendant increases in the risk of coronary heart disease, type 2 diabetes mellitus (T2DM), hypertension, dyslipidemia, stroke and certain cancers. ${ }^{2}$ Specific causes are still unclear; however, it is likely that a combination of metabolic, genetic, psychological and environmental factors all contribute to the obesity epidemic.

The number of bariatric surgical procedures performed has also increased dramatically. The appropriate use of bariatric surgery remains a subject of debate, with many physicians in the field remaining sceptical about it, in view of the risks associated with surgery. Ultimately, less invasive treatments are needed to address obesity and associated T2DM in a wider population of affected individuals. This review will discuss the clinical and physiological changes observed following bariatric surgery and examine how close we are to mimicking them through less invasive and potentially safer interventions. We have limited our discussion to the most modern non-surgical treatments that are currently available for clinical use in Europe and/or the in United States.

\begin{abstract}
METHODS
The source was a PubMed search used to identify relevant literature to the clinical efficacy and physiological effects of bariatric surgery procedures, lifestyle interventions, modern pharmacotherapy and less invasive devices on both obesity and T2DM. In view of the wide scope of the review, preferably randomised controlled clinical trials (RCTs) and definitive basic and clinical science publications were chosen with a particular focus to those published 2009-2013.
\end{abstract}

Types and clinical effectiveness of bariatric surgery

Bariatric surgery has been shown to be the most effective treatment for obesity and T2DM, both in large well-matched clinical studies and RCTs. ${ }^{3-8}$ Roux-en-Y gastric bypass (RYGB) and the adjustable gastric band (AGB) are the most commonly performed surgical procedures around the world. The RYGB procedure typically involves fashioning a 15 - to $20-\mathrm{ml}$ gastric pouch and creating a large new outlet that rapidly empties into the mid small intestine (Figure 1). The continuity of the bowel is restored via a jejunojejunal anastomosis, between the excluded biliopancreatic limb and the alimentary limb, performed $75-150 \mathrm{~cm}$ distally to the gastrojejunostomy. ${ }^{9}$ The gastric remnant is no longer exposed to food; gastric, pancreatic and biliary secretions still flow undiluted in the biliopancreatic limb and come in contact with food in the jejuno-jejunal anastomosis. It is normally performed laparoscopically and causes $25-30 \%$ weight loss, which is maintained for at least 20 years. ${ }^{4,10}$

The AGB technique involves the insertion of an adjustable silicone ring around the proximal aspect of the stomach, immediately below the

\footnotetext{
${ }^{1}$ Molecular and Metabolic Imaging Group, Imperial College London, MRC Institute of Clinical Sciences, London, UK and ${ }^{2}$ Department of Experimental Pathology, Conway Institute, School of Medicine and Medical Sciences, University College Dublin, Dublin, Ireland. Correspondence: Dr AD Miras, Molecular and Metabolic Imaging Group, Imperial College London, MRC Institute of Clinical Sciences, Du Cane Road Imperial Weight Centre, London W6 8RF, UK. 

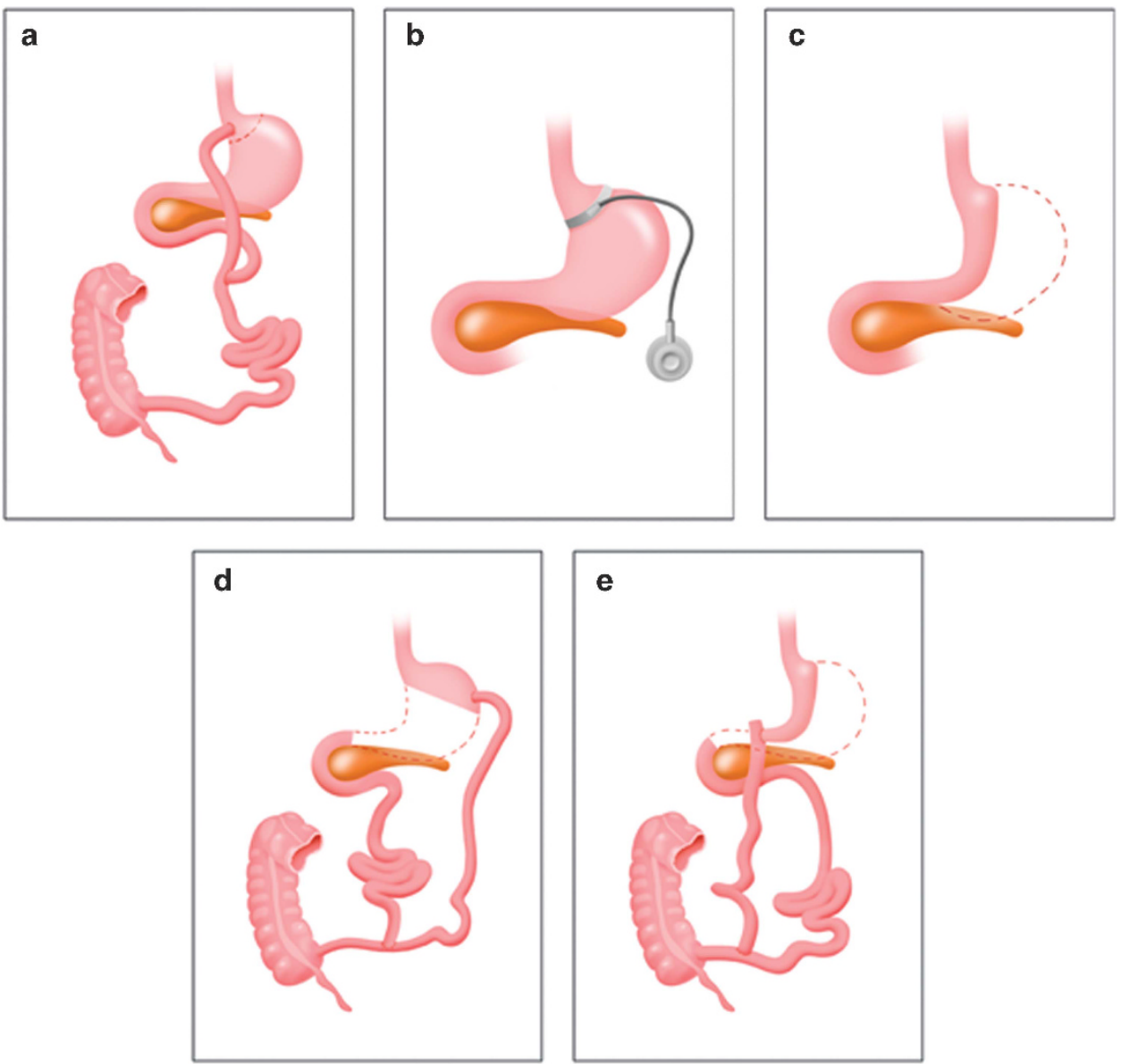

Figure 1. Anatomical manipulation of the surgical bariatric procedures. Bariatric procedures: (a) Roux-en-Y gastric bypass; (b) adjustable gastric banding; (c) vertical sleeve gastrectomy; (d) biliopancreatic diversion; (e) biliopancreatic diversion with duodenal switch.

gastro-oesophageal junction creating a small proximal pouch. The volume of fluid in the band is adjusted through injections in a subcutaneous port. The procedure results in $20-25 \%$ long-term weight loss. ${ }^{10,11}$ The vertical sleeve gastrectomy (VSG) is fashioned through the reduction in gastric volume by the laparoscopic removal of $70-80 \%$ of the stomach. Previously, VSG was performed as part of the duodenal switch procedure but is increasingly used as a stand-alone procedure that can cause a weight loss of $20-30 \%$ in the long term. ${ }^{12}$ Owing to increased rates of postoperative and nutritional complications, the biliopancreatic diversion and duodenal switch procedures are performed less frequently compared with the other procedures. $^{10,11}$

Bariatric surgery also results in significant glycaemic improvements in T2DM. Four RCTs have compared RYGB, AGB, VSG and biliopancreatic diversion to lifestyle and pharmacological interventions for obese patients with T2DM. ${ }^{5-8}$ Their results are consistent in that each of the procedures was superior to non-surgical therapies in terms of reductions in weight, glycaemia and glucose-lowering medication use.

The benefits of bariatric surgery extend beyond improvements in weight and glycaemic control; patients also exhibit reductions in overall and cardiovascular morbidity and mortality rates, as well as a reduction in cancer incidence. ${ }^{3,4,13}$ Although some early improvements in diabetic retinopathy and nephropathy have been observed, ${ }^{14}$ the long-term impact of bariatric surgery on microvascular complications is not known. Currently, there are no data from RCTs to support the use of surgery for comorbidities that are frequently associated with obesity including non-alcoholic fatty liver disease, subfertility, renal disease and functional impairment. In terms of obstructive sleep apnoea, AGB resulted in greater weight loss but did not improve the apnoea hypopnoea index significantly more than non-surgical weight loss therapies. ${ }^{15}$ In the absence of sufficient evidence, the choice of technique depends on patient and multidisciplinary team preference, local expertise and funding.

\section{Complications of bariatric surgery}

As with any intervention, bariatric surgery is not without complications. The most serious complications associated with bariatric surgery include postoperative sepsis, anastomotic leaks, bleeding and venous thromboembolism, including fatal pulmonary embolism. ${ }^{16}$ The risk of early mortality after bariatric surgery ranges from 0.1 to $2.0 \%$ depending on the procedure. ${ }^{10}$ The longitudinal assessment of bariatric surgery consortium reported a 30-day postoperative mortality rate of $0.3 \%$ with RYGB. ${ }^{17}$ Factors associated with increased mortality include male gender, age older than 65 years, reduced cardiorespiratory fitness levels and limited surgeon experience. ${ }^{16}$

Long-term nutritional deficiencies may occur in some bariatric surgery patients due to changes in the anatomy of the gastrointestinal tract with surgery. ${ }^{18}$ Deficiencies in vitamin $B_{12}$, folate and iron are not uncommon early after surgery and evidence of calcium, vitamin $\mathrm{D}$ and trace element deficiencies can also occur months to years after the procedure. ${ }^{18}$

Although bariatric surgery has known beneficial effects in terms of T2DM remission, it may result in recurrent postprandial hypoglycaemia in some patients, which may signal an extreme metabolic reaction to surgery. The Swedish bariatric surgery registry found that the risk of hypoglycaemia and related diagnoses were higher in bariatric surgery patients compared with the general population, although the absolute risk of these events remained small. ${ }^{19}$

Overall, modern bariatric surgery has an acceptable risk/benefit profile, with careful patient selection and the availability of an appropriately experienced multidisciplinary team that is responsible for patient care in both the preoperative and postoperative periods.

Appetite, energy expenditure and food preferences after bariatric surgery

Although RYGB was originally designed to cause gastrointestinal restriction and malabsorption, an increasing volume of evidence supports that the 
surgery works by reducing hunger and increasing satiation after a meal. ${ }^{20}$ A number of studies suggest that diet-induced energy expenditure increases after RYGB, further aiding weight loss. ${ }^{21,22}$ Patients also witness a healthy shift in eating behaviour, away from calorically dense high-fat and sweet food to low-calorie alternatives. ${ }^{23}$ The mechanisms behind this are not fully clear yet but may include alterations in food reward, changes in taste function or other consequences relating to the dumping syndrome. ${ }^{24,25}$ Contrary to malabsorptive procedures, such as the biliopancreatic diversion and duodenal switch, RYGB results in minimal fat and no carbohydrate malabsorption. ${ }^{26,27}$

There is intense interest in the mechanisms through which VSG and AGB work. Following VSG, patients report reductions in appetite to those experienced after RYGB. ${ }^{28}$ Energy expenditure appears to remain either stable or shows a tendency to decrease in animal models of VSG. ${ }^{29,30}$ In terms of the $A G B$, higher intraluminal pressure on vagal afferents in the stomach may facilitate reductions in hunger and meal size after AGB. ${ }^{31,32}$ Food choices may either not change or even deteriorate, ${ }^{33}$ whereas energy expenditure has not been quantified after AGB.

Gut hormones are some of the mediators of reduced hunger, increased satiation and consequent weight loss after RYGB and VSG surgery. Specifically, RYGB and VSG have been shown to enhance meal-stimulated hormonal secretion of anorexigenic insulin, peptide tyrosine tyrosine (PYY), glucagon-like peptide 1 (GLP-1), ${ }^{20,28,34}$ which is sustained for at least 10 years (in the case of RYGB). ${ }^{35}$ The rise in levels of these hormones after VSG is intriguing, but may be because of increased gastric emptying, propelling nutrients to the mid and distal intestine. ${ }^{36}$ The AGB does not significantly alter the plasma levels of these hormones. ${ }^{20,37}$

Owing to the variability in the laboratory techniques used to measure orexigenic ghrelin, it is currently unclear what happens to this hormone after RYGB; ${ }^{38}$ however, reasonable evidence exists that it decreases after VSG and increases after AGB. ${ }^{39}$ Obestatin, which is a hormone produced from the ghrelin gene but has anorexigenic action and antagonises the effects of ghrelin, has been shown to increase after VSG but remains unaltered after RYGB. ${ }^{40}$

Plasma leptin levels are decreased by all the three procedures; however, this is not followed by the compensatory changes in eating behaviour that accompany diet-induced weight loss. The increase in anorexigenic gut hormones seen after RYGB and VSG and the increased vagal stimulation after AGB appear to be enough to counterbalance the effects of lower leptin levels on hunger and weight regain. There is no evidence from animal models to suggest that leptin sensitivity is improved beyond that expected for weight loss per se. ${ }^{29}$

More recently, other novel mediators that may contribute to weight loss have surfaced. In a series of very elegant experiments, the transfer of gut microbiota from mice that have undergone RYGB to germ-free mice leads to $5 \%$ weight loss in the latter group, potentially through altered shortchain fatty acid production and signalling. ${ }^{41}$

\section{T2DM after bariatric surgery}

Beta cell function. All bariatric surgery procedures cause glycaemic improvements through weight loss per se; however, improvements are more pronounced after RYGB and VSG and start becoming apparent before weight loss. ${ }^{42,43} \mathrm{~A}$ potential reason underlying this may be the improvements in $\beta$-cell function after these procedures. After both RYGB and VSG, the early postprandial release of insulin is increased within a few days after surgery but also remains exaggerated after weight loss has been achieved. ${ }^{4-47}$ On the contrary, total insulin release (expressed as area under the curve) is appropriately reduced after weight loss and in the face of reduced peripheral insulin resistance. ${ }^{45}$ AGB results in gradual weight loss and appropriate reductions in total postprandial insulin release but without the exaggerated early responses seen after RYGB or VSG. ${ }^{45}$

A human mechanistic study has shown that the early increases in insulin release after RYGB is partly because of the incretin effect of GLP-1.48 However, it has also been suggested that the negative energy balance achieved after bariatric surgery may be partly responsible for the early marked improvement of $\beta$-cell function. ${ }^{49}$. Even though this theory may well apply in the context of calorie intake reduction after bariatric surgery, it does not explain the very different insulin release profiles between RYGB/VSG and AGB.

Insulin resistance. The RYGB, AGB and VSG procedures facilitate reductions in peripheral insulin resistance directly as a result of gradual weight loss. $^{50}$ Interestingly, however, in some human studies, hepatic insulin resistance, is reduced within days after RYGB before any significant weight loss has taken place. ${ }^{51,52}$ Whereas this may be a direct result of a negative energy balance, ${ }^{49}$ the reduction in hepatic insulin resistance in some studies is greater in patients after RYGB compared with patients undergoing similar caloric restriction after AGB or a very-low-calorie diet. ${ }^{44,51,52}$ Even though these findings are not universal, they suggest that the bypass of the proximal bowel may have caloric intake and weight lossindependent effects on hepatic insulin resistance and hepatic glucose output.

Gut nutrient sensing. The role of portal vein glucose sensing became apparent in an elegant study of animal models that underwent a modified bypass procedure in which intestinal glucose production was increased after surgery. This led to higher levels of glucose in the portal vein and triggered a neural cascade through afferent and efferent vagal fibres resulting in lower hepatic glucose output. ${ }^{53}$ In animal models of the duodeno-jejunal bypass, jejunal nutrient sensing has also been shown to exert profound control on hepatic glucose output in a similar manner. ${ }^{54}$ Exposure of the jejunum to undigested nutrients following RYGB (and perhaps VSG) may explain the reductions in hepatic glucose output seen early surgery; however, such mechanistic studies have not been performed in humans as yet.

Bile acids. The search for the mechanisms underlying weight loss and glycaemic improvements after bariatric surgery is gradually revealing numerous novel metabolic targets. Whereas gut hormones affect insulin secretion after bariatric surgery, bile acids may also exert a significant physiological effect. Bile acids have been shown not only to increase gut hormone production but also to reduce food intake, gluconeogenesis, insulin resistance and even increase energy expenditure through their actions on the FXR and TGR-5 receptors in the periphery and/or in the brain. ${ }^{55}$ Plasma bile acids are elevated after RYGB and VSG, but not AGB, and negatively correlate with post-prandial glycaemic excursions. ${ }^{56,57}$ However, no mechanistic studies have clearly defined their role after RYGB or VSG so far.

Table 1 summarises the available evidence on the physiological changes that take place after bariatric surgery.

\section{Lifestyle modification}

Appetite reduction is a compelling goal for long-term weight loss and the resolution of the metabolic effects of morbid obesity. The appeal of abundant highly palatable food that influences eating patterns can make caloric restriction an unachievable goal for many individuals. In obese patients who have achieved weight loss, clinical data suggest the presence of compensatory mechanisms that may lead to weight regain. ${ }^{58}$ One study reported that overweight and obese patients who underwent a 10-week weight loss programme had significantly lower levels of leptin, PYY, CCK, insulin and amylin and significant increases in ghrelin levels from baseline. These differences persisted at 1 year and were accompanied by significant increases in appetite and preoccupation with food. ${ }^{58}$

Therefore, once weight loss has been achieved, appetite control is critical to prevent subsequent regain of weight. The effect of nutrient content on weight maintenance was examined in overweight or obese adults who had achieved at least an $8 \%$ reduction in body weight with a very-low-calorie diet. ${ }^{59}$ Individuals who completed a high-protein, lowglycaemic index diet regimen for 26 weeks following initial weight loss exhibited a higher maintenance rate of weight loss compared with those who completed a low-protein, high-glycaemic index diet. Furthermore, individuals assigned to the high-protein, low-glycaemic index diet continued to lose weight over the course of the study, whereas participants assigned to the low-protein, high-glycaemic index diet demonstrated significant weight regain. Diets high in protein and low in carbohydrates appear to be superior in the reduction of hunger and their ketogenic effects may have a role. ${ }^{60}$

In the context of T2DM, a very-low-calorie diet of $600 \mathrm{kCal}$ had impressive short-term effects in reducing peripheral and hepatic insulin resistance, hepatic glucose output, and liver and pancreatic triacylglycerol. ${ }^{49}$ The diet also led to improvements in $\beta$-cell function and the authors concluded that part of the pathophysiology of T2DM can be reversed by energy intake restriction. This study sent a positive message to patients; however, the long-term success rate of such a strict dietary modification remains uncertain. However, even with little or no weight loss, high-protein, low-carbohydrate, low-glycaemic index and Mediterranean diets can also reduce cardiovascular risk or events in patients with or without T2DM. ${ }^{61,62}$ More recently, the LOOK AHEAD RCT 


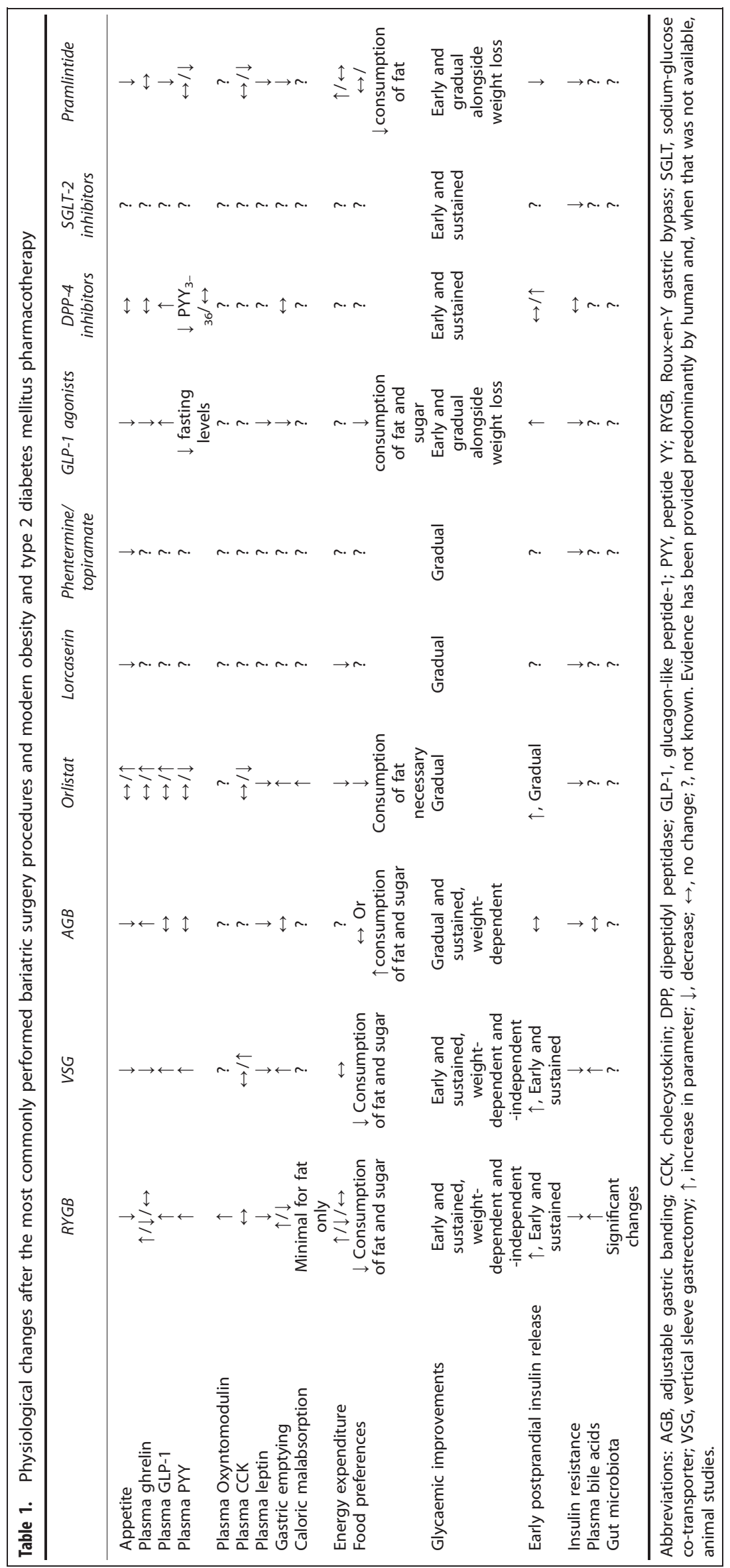


reported that intensive lifestyle modification, including only moderate caloric restriction, resulted in higher rates of T2DM remission at 4 years (7.3\%) compared with standard education $(2.0 \%){ }^{63}$ Even though the authors commented that these rates were low in absolute terms and did not translate in superior improvements in cardiovascular outcomes, ${ }^{64}$ the patient population was relatively old, had long T2DM duration and the criteria used for remission were stringent. These results suggest that early and intensive lifestyle intervention in T2DM can have positive effects and even obviate the need for medications in some patients for a reasonable length of time during the course of the disease.

\section{Obesity pharmacotherapy}

The ability to achieve weight loss and maintenance with pharmacological agents has been an attractive yet elusive goal. For instance, although drugs such as rimonabant and sibutramine were previously used as a pharmacological strategy for obesity management, these agents were withdrawn following reports of increased risks of psychological and cardiovascular adverse events, respectively. ${ }^{65,66}$ The discontinuation of these medications has not only led to longer and more thorough assessment of adverse events before and after drug marketing but also hopefully to the development of weight-loss agents that are more selective in their mode of action either in the brain or in the periphery.

Orlistat is the only drug that has stood the test of time in many countries around the world. It decreases fat absorption by 30\% through the inhibition of pancreatic and gastric lipase. In practice, it works by making patients consciously reduce their fat intake to avoid unpleasant and socially embarrassing oily diarrhoea. A number of RCTs and meta-analyses have shown small decreases in weight of $2.9 \mathrm{~kg},{ }^{67}$ with beneficial effects on cardiometabolic risk factors and reductions in the incidence of T2DM. ${ }^{68}$ Gastrointestinal side effects remain common, whereas the rare occurrence of severe liver injury has also been reported. ${ }^{67}$

After 13 years with no new drug approvals, in 2012 the US FDA sanctioned two agents that reduce appetite and lead to modest weight loss. Lorcaserin is a serotonin $2 \mathrm{C}$ (5-hydroxytryptamine $[5-\mathrm{HT}]_{2 \mathrm{C}}$ ) agonist that leads to reductions in food intake and perhaps food reward. The $5-\mathrm{HT}_{2} \mathrm{C}$ receptor is not only located in the hypothalamus but also in some of the reward areas of the brain, including the prefrontal cortex, nucleus accumbens and amygdala. Phase 3 trials of 52-week duration have demonstrated that patients on the 10-mg, twice-daily dose lose an extra $2.9-3.6 \%$ of weight compared with patients on placebo. ${ }^{69-71}$ This was also accompanied by a $0.5 \%$ absolute decrease in $\mathrm{HbA} 1 \mathrm{c}$, improvements in lipids, blood pressure and waist circumference and no significant increase in the rate of cardiac valvular disease compared with placebo. The most frequent side effects of headache, dizziness, dry mouth and nausea were mild and tolerated by most patients, whereas symptomatic hypoglycaemia was reported significantly more frequently by diabetic patients in the intervention compared with the placebo arm.

The combination of phentermine and the antiepileptic topiramate has also been recently approved by the US FDA. Phentermine is a sympathomimetic drug, and its use with fenfluramine was discontinued in 1997 because of the association of fenfluramine with cardiac valvular disease and pulmonary arterial hypertension. Topiramate attenuates appetite through mechanisms that remain to be elucidated. The highdose combination of the two medications led to an impressive $7.5-8.7 \%$ placebo-adjusted weight loss, a $0.4 \%$ absolute reduction in $\mathrm{HbA} 1 \mathrm{c}$ and a decrease in the incidence of T2DM at 2 years compared with placebo. ${ }^{72-74}$ Side effects included paraesthesiae, constipation and dry mouth. Even though small increases in heart rate (by 1.7 beats per min, but no adverse clinical events) and discontinuation of the drug because of depression/ anxiety and cognitive impairment were observed, the use of controlled release topiramate and lower doses of phentermine, as a fixed dose combination, may reduce the incidence of these potentially serious and problematic adverse events. The drug's longer-term effects on cardiovascular and psychiatric morbidity remain to be determined.

In summary, the two novel centrally acting medications may mimic in part the effect of bariatric surgery in reducing hunger; however, certainly their initial use should be cautious, and close long-term patient monitoring is essential.

\section{Modern T2DM pharmacotherapy}

The drug discovery output for T2DM drugs has been much more fruitful and successful, mainly owing to the use of gut hormone analogues, which mimic endogenously produced 'natural' signals, rather than entirely synthetic agents with potentially diffuse receptor affinity.
GLP-1 receptor agonists. Apart from its anorexigenic effects, GLP-1 acts as an incretin hormone to increase insulin release and lower glucagon secretion and hepatic glucose output. ${ }^{75}$ The four available GLP-1 receptor agonists are the short-acting exenatide twice-daily (BID) and lixisenatide, and the longer-acting exenatide extended release (ER) and liraglutide once daily. Head-to-head trials between exenatide BID and ER have shown the superior efficacy of the once-weekly preparation, which in addition to oral therapy, reduced $\mathrm{HbA} 1 \mathrm{c}$ by $1.6-1.9 \%$ and weight by $2.3-3.7 \mathrm{~kg}$ compared with respective absolute reductions of $0.9-1.5 \%$ and $1.4-3.6 \mathrm{~kg}$ with exenatide BID. ${ }^{76,77}$ Trials comparing liraglutide with exenatide BID in addition to oral therapy have shown that at a dose of $1.8 \mathrm{mg}$ liraglutide was more effective in reducing $\mathrm{HbA1c}$ (absolute reduction $1.12 \%$ versus $0.79 \%)$ but not weight $\left(-3.2\right.$ versus $-2.8 \mathrm{~kg}$; not significant). ${ }^{78}$ These medications reduce blood pressure in a weight-independent manner and even improve $\beta$-cell function as assessed by the homoeostasis model assessment of $\beta$-cell function and proinsulin/insulin ratio. ${ }^{79,80}$ The superior efficacy of liraglutide may be because of its lower immunogenicity. ${ }^{81}$ Lixisenatide was the last GLP-1 receptor agonist to be launched in the market. On the basis of the data from the GetGoal programme of clinical trials, it leads to placebo-controlled $\mathrm{HbA} 1 \mathrm{c}$ reductions of $0.3-0.9 \%$ (starting $\mathrm{HbA} 1 \mathrm{c} \sim 8.0-8.5 \%$ ) and weight changes of -2.7 to $+0.3 \mathrm{~kg}$ (starting body mass index $\left.\sim 30-34 \mathrm{~kg} \mathrm{~m}^{-2}\right){ }^{82,83}$ Lixisenatide is particularly effective in controlling postprandial glucose excursions and may therefore be clinically useful when used in combination treatment with long-acting insulins. Whereas these compounds are currently used in the management of T2DM, an expanded role of high-dose liraglutide in weight-loss initiation and maintenance is currently under investigation. ${ }^{84}$

A major advantage of these drugs is their relatively favourable side effect profile. On the basis of the trials mentioned previously, the rates of hypoglycaemia are relatively low, whereas nausea, vomiting and diarrhoea, although common, are well tolerated by most patients. Nausea tends to be transient in the majority of cases and is less common with the longeracting preparations. ${ }^{84}$ Longer-term studies are necessary to determine cardiovascular and safety outcomes, and in particular, answer specific concerns over the association with pancreatitis, pancreatic and thyroid C-cell cancer, and increases in heart rate with exenatide and liraglutide.

DPP-4 inhibitors. The four available dipeptidyl peptidase-4 (DPP-4) inhibitors are sitagliptin, vildagliptin, saxagliptin and linagliptin. They all inhibit the enzyme that degrades GLP-1, thus raising the tissue levels. The major advantage of these medications is their oral route of administration and the relatively low incidence of hypoglycaemia and gastrointestinal side effects. Compared with GLP-1 agonists, they are less effective in improving glycaemia ( $\mathrm{HbA} 1 \mathrm{c}$ absolute reductions of $0.5-1.0 \%$ ) and are weight neutral. ${ }^{85}$ It is interesting to note that DPP-4 inhibitors are only slightly less efficacious compared with GLP-1 agonists, even though plasma levels while on DPP-4 treatment are significantly lower to those seen when on GLP-1 analogue therapies. A number of elegant studies have shown that the majority of physiological action of DPP-4 inhibitors is exerted through local, and not just plasma, increases in GLP-1 and stimulation of the gut wall and portal vein vagal receptors. ${ }^{86,87}$ As DPP-4 is also necessary for the activation of anorexigenic gut hormones, such as PYY, its inhibition may be responsible for the weight neutrality of these agents.

Amylin mimetics. Pramlintide is an injectable amylin-mimetic that has been approved by the FDA for the treatment of T1DM and T2DM. Amylin is a hormone co-secreted with insulin by the $\beta$ cell and has multiple physiological actions including the reduction in gastric emptying, food intake, post-prandial glucose and glucagon release. In the context of T2DM, it has been shown to cause small placebo-subtracted absolute reductions in $\mathrm{HbA} 1 \mathrm{c}$ of $0.2-0.4 \%$ (even with high starting $\mathrm{HbA} 1 \mathrm{c}$ of $8.2-9.3 \%$ ) and weight loss of $2.1-2.3 \mathrm{~kg}$ (starting weight $97-103 \mathrm{~kg}$ ). ${ }^{88}$ Side effects include temporary nausea and mild to moderate hypoglycaemia in T2DM. Its high cost and injectable mode of delivery have somewhat limited its clinical use.

SGLT-2 inhibitors. The newest class of agents released for clinical use in some parts of the world is the sodium-glucose co-transporter 2 inhibitors that lower plasma glucose, independently of insulin resistance and secretion, by reducing renal reabsorption. ${ }^{89}$ The placebo-subtracted absolute reductions in $\mathrm{HbA} 1 \mathrm{C}$ with the first agent of this class, dapagliflozin, are modest $(0.4-0.8 \%$, starting $\mathrm{HbA} 1 \mathrm{c} \sim 7.8-8.0 \%)$, but are maintained at least up to 2 years, whereas the excretion of glucose is beneficial for weight loss $(2.0-3.0 \mathrm{~kg}){ }^{89}$ Dapagliflozin also leads to 
reductions in systolic blood pressure of 4-5 and diastolic blood pressure of $2-3 \mathrm{~mm} \mathrm{Hg}$, partially as a result of its diuretic effects and the inhibition of the renin-angiotensin system in the kidney. The route of administration of dapagliflozin is oral and the rates of hypoglycaemia with the drug are low. The major benefit of this class of drugs is that they can be used at any stage of the disease process, in combination with most other glucoselowering medications, and may even preserve beta cell function. Adverse effects include urinary tract and genital infections and volume depletion, and there are concerns regarding the rare incidence of breast and bladder cancer and liver injury. ${ }^{89}$

In summary, the treatment of T2DM has undergone a metamorphosis in the last 7 years or so because of the addition of a number of new classes of glucose-lowering medications. These not only have reasonable effects on glycaemia but, more importantly, promote clinically significant weight loss. However, long-term data on cardiovascular outcomes and serious adverse events are vital before these agents' position in the treatment algorithm for T2DM is secure.

\section{Devices}

The most promising of the devices currently in use as less invasive treatments for obesity and T2DM is the duodenal-jejunal bypass liner (EndoBarrier, GI Dynamics, Lexington, MA, USA). It is made of a plastic polymer, is $60 \mathrm{~cm}$ in length and is inserted endoscopically in such a way as to line the proximal small bowel and exclude contact of food with its walls. By mimicking the physiological changes in the biliopancreatic limb (one of the components of RYGB), this device leads to weight reductions of $10-20 \% .^{90,91}$ Its metabolic effects are more impressive, with absolute reductions in $\mathrm{HbA} 1 \mathrm{c}$ of $\sim 1.2-2.3 \%$ (starting $\mathrm{HbA} 1 \mathrm{C} 7.3-9.1 \%$ ). ${ }^{92-94}$ The device lowers fasting glucose within 1 week of insertion; however, the mechanism of action remains unclear. The early glycaemic improvements suggest beneficial effects on hepatic insulin resistance and hepatic glucose output. The exposure of the proximal small bowel to undiluted bile acids and of the distal small bowel to undigested nutrients may have a vital physiological role in the efficacy of this device. ${ }^{54}$ The major limitations of this intervention are that it has to be explanted electively at 6-12 months and may need to be prematurely removed because of severe abdominal pain, vomiting, obstruction and bleeding in up to $30 \%$ of cases. As with all medical devices, it needs to undergo further comprehensive evaluation through clinical trials before it is widely used in clinical practice.

Gastric stimulators, which are inserted endoscopically, work by reducing hunger and increasing satiation. Their mode of action is unclear but may include inhibition of efferent vagal signalling resulting in gastric detention, reduced gastric emptying and therefore early satiation. ${ }^{95}$ They may also have stimulatory effects on afferent vagal fibres, which signal satiation to the hypothalamus via the brainstem. Even though open-labelled studies reported promising results, the findings from RCTs have been less encouraging. ${ }^{96}$ Nevertheless, there is room for the technology to improve and promote weight loss more safely than bariatric surgery.

Gastric balloons are fluid-filled silicone sacs inserted endoscopically and reduce weight by increasing early satiety. The current published studies have not shown their superiority to conventional weight-loss treatments. ${ }^{97}$ However, gastric balloons can still be useful as a temporary measure to reduce anaesthetic risk and therefore act as a bridge to elective orthopaedic, bariatric, cardiac or transplantation surgery.

\section{DISCUSSION AND CONCLUSION}

So can we mimic the clinical efficacy of surgery with less invasive therapies? On the basis of the most recent studies, the answer is that at the moment we cannot, but we are getting closer. The SOS study compared bariatric surgery to lifestyle and behavioural interventions. The study started recruiting patients in 1987, and modern obesity pharmacotherapy was not approved in Sweden until 1998. Additionally, the lifestyle support that patients received was very heterogeneous and in some cases not intensive at all. Nevertheless, weight loss and glycaemic improvement outcomes were far better with surgery, even after 20 years of followup. $3,4,98,99$

The most recent RCTs, which have focused on patients with T2DM, tell a slightly different story. In a head-to-head trial between biliopancreatic diversion, RYGB and modern medical care, the surgical groups did better in terms of glycaemic control and weight loss than the medically treated group, but to a lesser degree when compared to the SOS study. ${ }^{5}$ Medical patients lost $4.7 \%$ of weight, their $\mathrm{HbA} 1 \mathrm{c}$ improved by $8.4 \%$ (relative reduction) and the blood pressure and lipid outcomes were not statistically different compared with the RYGB group at 24 months. In an RCT that compared RYGB with VSG and modern medical care, the patients in the latter group also lost weight, improved their glycaemic control, cardiometabolic factors and inflammation at 12 months. ${ }^{6}$ Whereas surgery was still superior to medical care, the combination of the two was synergistic in its positive outcomes. Even though the combination of surgical and nonsurgical interventions has been practiced successfully for years in other fields of metabolic and endocrine medicines (for example, pituitary disease), the concept of providing bariatric surgery as part of a treatment algorithm, together with - and not instead of-less invasive therapies is novel and one that is increasingly popular. ${ }^{6,8}$

The most up-to-date lifestyle modification therapies, pharmacotherapy and medical devices were only partially studied in these trials. A 'medical bypass' alternative to bariatric surgery may not be as far in the future as we previously thought. Weight loss of significant magnitude could potentially be achieved through the use of lorcaserin, phentermine/topiramate, orlistat, gut hormone analogues and medical devices, not in isolation but in combination. In the context of T2DM associated with obesity, we would suggest that the effect of RYGB on reducing hepatic insulin resistance can be mimicked by the endoscopically placed duodenal-jejunal bypass liner and that some of the effect of RYGB on enhanced insulin secretion can be mimicked by GLP-1 agonists. In addition, there may be a synergism to reduce body weight between the endoscopically placed duodenal-jejunal bypass liner, GLP-1 agonists, DPP-4 inhibitors, pramlintide and SGLT-2 inhibitors. The weight loss and glycaemic improvements induced by these less invasive treatments could then be maintained on a high-protein, low-glycaemic index or Mediterranean diet. The clinical efficacy and safety of such combination therapies, together with gut hormone analogues and bile acid receptor agonists currently under development, could be compared with that of bariatric surgery in large-scale RCTs. These trials will inform us as to whether the beneficial clinical and physiological effects of bariatric surgery can be mimicked but also whether this can be achieved with a reduced morbidity and mortality burden.

We conclude that the physician's armamentarium against obesity and associated T2DM is getting stronger through the use of specific dietary modifications, novel medical devices and pharmacotherapy. Although there are no magic bullets, an integrated multimodal approach may yield success. Non-surgical interventions that mimic the metabolic benefits of bariatric surgery remain tenable alternatives for many patients and health-care professionals.

\section{CONFLICT OF INTEREST}

The authors declare no conflict of interest.

\section{ACKNOWLEDGEMENTS}

CWleR and ADM conceived the idea and are guarantors of the intellectual content of the manuscript, while supportive medical writing and research assistance was provided by Roderick Sayce, BSc, MBA, Complete Publication Solutions, Horsham, PA, USA. Writing support was sponsored by Novo Nordisk, A/S. ADM is funded by the Medical Research Council Research Training Fellowship G0902002.

\section{AUTHOR CONTRIBUTIONS}

CWleR and ADM made substantial contributions to the conception and design of the manuscript, aided in drafting and revising the article, and approved the final version to be published. 


\section{REFERENCES}

1 Azagury DE, Lautz DB. Obesity overview: epidemiology, health and financial impact, and guidelines for qualification for surgical therapy. Gastrointest Endosc Clin N Am 2011; 21: 189-201.

2 Kopelman P. Health risks associated with overweight and obesity. Obes Rev 2007; 8(Suppl 1): 13-17.

3 Sjostrom L, Narbro K, Sjostrom CD, Karason K, Larsson B, Wedel H et al. Effects of bariatric surgery on mortality in Swedish obese subjects. N Engl J Med 2007; 357: 741-752.

4 Sjostrom L, Peltonen $\mathrm{M}$, Jacobson $\mathrm{P}$, Sjostrom CD, Karason $\mathrm{K}$, Wedel $\mathrm{H}$ et al. Bariatric surgery and long-term cardiovascular events. JAMA 2012; 307: 56-65.

5 Mingrone G, Panunzi S, De Gaetano A, Guidone C, laconelli A, Leccesi L et al. Bariatric surgery versus conventional medical therapy for type 2 diabetes. $N$ Engl J Med 2012; 366: 1577-1585.

6 Schauer PR, Kashyap SR, Wolski K, Brethauer SA, Kirwan JP, Pothier CE et al. Bariatric surgery versus intensive medical therapy in obese patients with diabetes. N Engl J Med 2012; 366: 1567-1576.

7 Dixon JB, O'Brien PE, Playfair J, Chapman L, Schachter LM, Skinner S et al. Adjustable gastric banding and conventional therapy for type 2 diabetes: a randomized controlled trial. JAMA 2008; 299: 316-323.

8 Ikramuddin S, Korner J, Lee WJ, Connett JE, Inabnet WB, Billington CJ et al. Roux-en-Y gastric bypass vs intensive medical management for the control of type 2 diabetes, hypertension, and hyperlipidemia: the Diabetes Surgery Study randomized clinical trial. JAMA 2013; 309: 2240-2249.

9 Olbers T, Lonroth H, Fagevik-Olsen M, Lundell L. Laparoscopic gastric bypass: development of technique, respiratory function, and long-term outcome. Obes Surg 2003; 13: 364-370.

10 Buchwald $\mathrm{H}$, Avidor $\mathrm{Y}$, Braunwald $\mathrm{E}$, Jensen MD, Pories $\mathrm{W}$, Fahrbach $\mathrm{K}$ et al. Bariatric surgery: a systematic review and meta-analysis. JAMA 2004; 292: 1724-1737.

11 O'Brien PE, McPhail T, Chaston TB, Dixon JB. Systematic review of medium-term weight loss after bariatric operations. Obes Surg 2006; 16: 1032-1040.

12 Brethauer SA, Hammel JP, Schauer PR. Systematic review of sleeve gastrectomy as staging and primary bariatric procedure. Surg Obes Relat Dis 2009; 5: 469-475.

13 Sjostrom L, Gummesson A, Sjostrom CD, Narbro K, Peltonen M, Wedel H et al. Effects of bariatric surgery on cancer incidence in obese patients in Sweden (Swedish Obese Subjects Study): a prospective, controlled intervention trial. Lancet Oncol 2009; 10: 653-662.

14 Miras AD, Chuah LL, Lascaratos G, Faruq S, Mohite AA, Shah PR et al. Bariatric surgery does not exacerbate and may be beneficial for the microvascular complications of type 2 diabetes mellitus. Diabetes Care 2012; 35: e81.

15 Dixon JB, Schachter LM, O'Brien PE, Jones K, Grima M, Lambert G et al. Surgical vs conventional therapy for weight loss treatment of obstructive sleep apnea: a randomized controlled trial. JAMA 2012; 308: 1142-1149.

16 Bult MJ, van Dalen T, Muller AF. Surgical treatment of obesity. Eur J Endocrinol 2008; 158: 135-145.

17 Longitudinal Assessment of Bariatric Surgery (LABS) ConsortiumFlum DR, Belle SH, King WC, Wahed AS, Berk $P$ et al. Perioperative safety in the longitudinal assessment of bariatric surgery. N Engl J Med 2009; 361: 445-454.

18 Bal BS, Finelli FC, Shope TR, Koch TR. Nutritional deficiencies after bariatric surgery. Nat Rev Endocrinol 2012; 8: 544-556.

19 Marsk R, Jonas E, Rasmussen F, Naslund E. Nationwide cohort study of post-gastric bypass hypoglycaemia including 5040 patients undergoing surgery for obesity in 1986-2006 in Sweden. Diabetologia 2010; 53: 2307-2311.

20 le Roux CW, Aylwin SJ, Batterham RL, Borg CM, Coyle F, Prasad V et al. Gut hormone profiles following bariatric surgery favor an anorectic state, facilitate weight loss, and improve metabolic parameters. Ann Surg 2006; 243: 108-114.

21 Bueter M, Lowenstein C, Olbers T, Wang M, Cluny NL, Bloom SR et al. Gastric bypass increases energy expenditure in rats. Gastroenterology 2010; 138: 1845-1853.

22 Werling $\mathrm{M}$, Olbers T, Fandriks L, Bueter M, Lonroth $\mathrm{H}$, Stenlof $\mathrm{K}$ et al. Increased postprandial energy expenditure may explain superior long term weight loss after Roux-en-Y gastric bypass compared to vertical banded gastroplasty. PLoS One 2013; 8: e60280.

23 Mathes CM, Spector AC. Food selection and taste changes in humans after Roux-en-Y gastric bypass surgery: a direct-measures approach. Physiol Behav 2012; 107: 476-483.

24 Miras AD, Jackson RN, Jackson SN, Goldstone AP, Olbers T, Hackenberg T et al. Gastric bypass surgery for obesity decreases the reward value of a sweet-fat stimulus as assessed in a progressive ratio task. Am J Clin Nutr 2012; 96: 467-473.

25 le Roux CW, Bueter M, Theis N, Werling M, Ashrafian H, Lowenstein C et al. Gastric bypass reduces fat intake and preference. Am J Physiol Regul Integr Comp Physiol 2011; 301: R1057-R1066.
26 Odstrcil EA, Martinez JG, Santa Ana CA, Xue B, Schneider RE, Steffer KJ et al. The contribution of malabsorption to the reduction in net energy absorption after long-limb Roux-en-Y gastric bypass. Am J Clin Nutr 2010; 92: 704-713.

27 Wang G, Agenor K, Pizot J, Kotler DP, Harel Y, Van Der Schueren BJ et al. Accelerated gastric emptying but no carbohydrate malabsorption 1 year after gastric bypass surgery (GBP). Obes Surg 2012; 22: 1263-1267.

28 Karamanakos SN, Vagenas K, Kalfarentzos F, Alexandrides TK. Weight loss, appetite suppression, and changes in fasting and postprandial ghrelin and peptide-YY levels after Roux-en-Y gastric bypass and sleeve gastrectomy: a prospective, double blind study. Ann Surg 2008; 247: 401-407.

29 Stefater MA, Perez-Tilve D, Chambers AP, Wilson-Perez HE, Sandoval DA, Berger J et al. Sleeve gastrectomy induces loss of weight and fat mass in obese rats, but does not affect leptin sensitivity. Gastroenterology 2010; 138: 2426-24362436 e1-3.

30 Saeidi N, Nestoridi E, Kucharczyk J, Uygun MK, Yarmush ML, Stylopoulos N. Sleeve gastrectomy and Roux-en-Y gastric bypass exhibit differential effects on food preferences, nutrient absorption and energy expenditure in obese rats. Int J Obes (Lond) 2012; 36: 1396-1402.

31 Burton PR, Brown WA. The mechanism of weight loss with laparoscopic adjustable gastric banding: induction of satiety not restriction. Int J Obes (Lond) 2011; 35(Suppl 3): S26-S30.

32 Dixon AF, Dixon JB, O'Brien PE. Laparoscopic adjustable gastric banding induces prolonged satiety: a randomized blind crossover study. J Clin Endocrinol Metab 2005; 90: 813-819.

33 Ernst B, Thurnheer M, Wilms B, Schultes B. Differential changes in dietary habits after gastric bypass versus gastric banding operations. Obes Surg 2009; 19: 274-280.

34 Valderas JP, Irribarra V, Rubio L, Boza C, Escalona M, Liberona $Y$ et al. Effects of sleeve gastrectomy and medical treatment for obesity on glucagon-like peptide 1 levels and glucose homeostasis in non-diabetic subjects. Obes Surg 2011; 21: 902-909.

35 Dar MS, Chapman 3rd WH, Pender JR, Drake 3rd AJ, O'Brien K, Tanenberg RJ et al. GLP-1 response to a mixed meal: what happens 10 years after Roux-en-Y gastric bypass (RYGB)? Obes Surg 2012; 22: 1077-1083.

36 Shah S, Shah P, Todkar J, Gagner M, Sonar S, Solav S. Prospective controlled study of effect of laparoscopic sleeve gastrectomy on small bowel transit time and gastric emptying half-time in morbidly obese patients with type 2 diabetes mellitus. Surg Obes Relat Dis 2010; 6: 152-157.

37 Korner J, Inabnet W, Febres G, Conwell IM, McMahon DJ, Salas R et al. Prospective study of gut hormone and metabolic changes after adjustable gastric banding and Roux-en-Y gastric bypass. Int J Obes (Lond) 2009; 33: 786-795.

38 Pournaras DJ, le Roux CW. Obesity, gut hormones, and bariatric surgery. World J Surg 2009; 33: 1983-1988.

39 Langer FB, Reza Hoda MA, Bohdjalian A, Felberbauer FX, Zacherl J, Wenzl E et al. Sleeve gastrectomy and gastric banding: effects on plasma ghrelin levels. Obes Surg 2005; 15: 1024-1029.

40 Lee WJ, Chen CY, Ser KH, Chong K, Chen SC, Lee PC et al. Differential influences of gastric bypass and sleeve gastrectomy on plasma Nesfatin-1 and Obestatin levels in patients with type 2 diabetes mellitus. Curr Pharm Des 2013; 19: 5830-5835.

41 Liou AP, Paziuk M, Luevano JM Jr, Machineni S, Turnbaugh PJ, Kaplan LM. Conserved shifts in the gut microbiota due to gastric bypass reduce host weight and adiposity. Sci Transl Med 2013; 5: 178ra41.

42 Rubino F, Gagner M, Gentileschi P, Kini S, Fukuyama S, Feng J et al. The early effect of the Roux-en-Y gastric bypass on hormones involved in body weight regulation and glucose metabolism. Ann Surg 2004; 240: 236-242.

43 Basso N, Capoccia D, Rizzello M, Abbatini F, Mariani P, Maglio C et al. First-phase insulin secretion, insulin sensitivity, ghrelin, GLP-1, and PYY changes $72 \mathrm{~h}$ after sleeve gastrectomy in obese diabetic patients: the gastric hypothesis. Surg Endosc 2011; 25: 3540-3550.

44 Kashyap SR, Daud S, Kelly KR, Gastaldelli A, Win H, Brethauer S et al. Acute effects of gastric bypass versus gastric restrictive surgery on beta-cell function and insulinotropic hormones in severely obese patients with type 2 diabetes. Int J Obes (Lond) 2010; 34: 462-471.

45 Bradley D, Conte C, Mittendorfer B, Eagon JC, Varela JE, Fabbrini E et al. Gastric bypass and banding equally improve insulin sensitivity and beta cell function. J Clin Invest 2012; 122: 4667-4674.

46 Lee WJ, Ser KH, Chong K, Lee YC, Chen SC, Tsou JJ et al. Laparoscopic sleeve gastrectomy for diabetes treatment in nonmorbidly obese patients: efficacy and change of insulin secretion. Surgery 2010; 147: 664-669.

47 Peterli R, Wolnerhanssen B, Peters T, Devaux N, Kern B, Christoffel-Courtin C et al. Improvement in glucose metabolism after bariatric surgery: comparison of laparoscopic Roux-en-Y gastric bypass and laparoscopic sleeve gastrectomy: a prospective randomized trial. Ann Surg 2009; 250: 234-241. 
48 Salehi M, Prigeon RL, D'Alessio DA. Gastric bypass surgery enhances glucagon-like peptide 1-stimulated postprandial insulin secretion in humans. Diabetes $2011 ; 60$ 2308-2314.

49 Lim EL, Hollingsworth KG, Aribisala BS, Chen MJ, Mathers JC, Taylor R. Reversal of type 2 diabetes: normalisation of beta cell function in association with decreased pancreas and liver triacylglycerol. Diabetologia 2011; 54: 2506-2514.

50 Bradley D, Magkos F, Klein S. Effects of bariatric surgery on glucose homeostasis and type 2 diabetes. Gastroenterology 2012; 143: 897-912.

51 Pournaras DJ, Osborne A, Hawkins SC, Vincent RP, Mahon D, Ewings P et al. Remission of type 2 diabetes after gastric bypass and banding: mechanisms and 2 year outcomes. Ann Surg 2010; 252: 966-971.

52 Foo J, Krebs J, Hayes MT, Bell D, Macartney-Coxson D, Croft T et al. Studies in insulin resistance following very low calorie diet and/or gastric bypass surgery. Obes Surg 2011; 21: 1914-1920.

53 Troy S, Soty M, Ribeiro L, Laval L, Migrenne S, Fioramonti X et al. Intestinal gluconeogenesis is a key factor for early metabolic changes after gastric bypass but not after gastric lap-band in mice. Cell Metab 2008; 8: 201-211.

54 Breen DM, Rasmussen BA, Kokorovic A, Wang R, Cheung GW, Lam TK. Jejunal nutrient sensing is required for duodenal-jejunal bypass surgery to rapidly lower glucose concentrations in uncontrolled diabetes. Nat Med 2012; 18 950-955.

55 Thomas C, Pellicciari R, Pruzanski M, Auwerx J, Schoonjans K. Targeting bile-acid signalling for metabolic diseases. Nat Rev Drug Discov 2008; 7: 678-693.

56 Pournaras DJ, Glicksman C, Vincent RP, Kuganolipava S, Alaghband-Zadeh J, Mahon $\mathrm{D}$ et al. The role of bile after Roux-en-Y gastric bypass in promoting weight loss and improving glycaemic control. Endocrinology 2012; 153: 3613-3619.

57 Stefater MA, Sandoval DA, Chambers AP, Wilson-Perez HE, Hofmann SM, Jandacek $\mathrm{R}$ et al. Sleeve gastrectomy in rats improves postprandial lipid clearance by reducing intestinal triglyceride secretion. Gastroenterology 2011; 141: 939-949 e1-4.

58 Sumithran P, Prendergast LA, Delbridge E, Purcell K, Shulkes A, Kriketos A et al. Long-term persistence of hormonal adaptations to weight loss. N Engl J Med 2011; 365: 1597-1604.

59 Larsen TM, Dalskov SM, van Baak M, Jebb SA, Papadaki A, Pfeiffer AF et al. Diets with high or low protein content and glycemic index for weight-loss maintenance. N Engl J Med 2010; 363: 2102-2113.

60 Johnstone AM, Horgan GW, Murison SD, Bremner DM, Lobley GE. Effects of a high-protein ketogenic diet on hunger, appetite, and weight loss in obese men feeding ad libitum. Am J Clin Nutr 2008; 87: 44-55.

61 Ajala O, English P, Pinkney J. Systematic review and meta-analysis of different dietary approaches to the management of type 2 diabetes. Am J Clin Nutr 2013; 97: $505-516$

62 Estruch R, Ros E, Salas-Salvado J, Covas Ml, Corella D, Aros F et al. Primary prevention of cardiovascular disease with a Mediterranean diet. $N$ Engl J Med 2013; 368: 1279-1290.

63 Gregg EW, Chen H, Wagenknecht LE, Clark JM, Delahanty LM, Bantle J et al. Association of an intensive lifestyle intervention with remission of type 2 diabetes. JAMA 2012; 308: 2489-2496.

64 Wing RR, Bolin P, Brancati FL, Bray GA, Clark JM, Coday M et al. Cardiovascular effects of intensive lifestyle intervention in type 2 diabetes. N Engl J Med 2013 369: 145-154.

65 Samat A, Tomlinson B, Taheri S, Thomas GN. Rimonabant for the treatment of obesity. Recent Pat Cardiovasc Drug Discov 2008; 3: 187-193.

66 James WP, Caterson ID, Coutinho W, Finer N, Van Gaal LF, Maggioni AP et al. Effect of sibutramine on cardiovascular outcomes in overweight and obese subjects. N Engl J Med 2010; 363: 905-917.

67 Li Z, Maglione M, Tu W, Mojica W, Arterburn D, Shugarman LR et al. Meta-analysis: pharmacologic treatment of obesity. Ann Intern Med 2005; 142: 532-546.

68 Torgerson JS, Hauptman J, Boldrin MN, Sjostrom L. XENical in the prevention of diabetes in obese subjects (XENDOS) study: a randomized study of orlistat as an adjunct to lifestyle changes for the prevention of type 2 diabetes in obese patients. Diabetes Care 2004; 27: 155-161.

69 Smith SR, Weissman NJ, Anderson CM, Sanchez M, Chuang E, Stubbe S et al. Multicenter, placebo-controlled trial of lorcaserin for weight management. N Engl J Med 2010; 363: 245-256.

70 Fidler MC, Sanchez M, Raether B, Weissman NJ, Smith SR, Shanahan WR et al. A one-year randomized trial of lorcaserin for weight loss in obese and overweight adults: the BLOSSOM trial. J Clin Endocrinol Metab 2011; 96: 3067-3077.

71 O'Neil PM, Smith SR, Weissman NJ, Fidler MC, Sanchez M, Zhang J et al. Randomized placebo-controlled clinical trial of lorcaserin for weight loss in type 2 diabetes mellitus: the BLOOM-DM study. Obesity (Silver Spring) 2012; 20: 1426-1436.

72 Gadde KM, Allison DB, Ryan DH, Peterson CA, Troupin B, Schwiers ML et al. Effects of low-dose, controlled-release, phentermine plus topiramate combination on weight and associated comorbidities in overweight and obese adults (CONQUER): a randomised, placebo-controlled, phase 3 trial. Lancet 2011; 377 $1341-1352$

73 Garvey WT, Ryan DH, Look M, Gadde KM, Allison DB, Peterson CA et al. Two-year sustained weight loss and metabolic benefits with controlled-release phentermine/topiramate in obese and overweight adults (SEQUEL): a randomized placebo-controlled, phase 3 extension study. Am J Clin Nutr 2012; 95: 297-308.

74 Allison DB, Gadde KM, Garvey WT, Peterson CA, Schwiers ML, Najarian T et al. Controlled-release phentermine/topiramate in severely obese adults: a randomized controlled trial (EQUIP). Obesity (Silver Spring) 2012; 20: 330-342.

75 Prigeon RL, Quddusi S, Paty B, D'Alessio DA. Suppression of glucose production by GLP-1 independent of islet hormones: a novel extrapancreatic effect. Am J Physiol Endocrinol Metab 2003; 285: E701-E707.

76 Drucker DJ, Buse JB, Taylor K, Kendall DM, Trautmann M, Zhuang D et al. Exenatide once weekly versus twice daily for the treatment of type 2 diabetes: a randomised, open-label, non-inferiority study. Lancet 2008; 372: 1240-1250.

77 Blevins T, Pullman J, Malloy J, Yan P, Taylor K, Schulteis C et al. DURATION-5: exenatide once weekly resulted in greater improvements in glycemic control compared with exenatide twice daily in patients with type 2 diabetes. J Clin Endocrinol Metab 2011; 96: 1301-1310.

78 Buse JB, Rosenstock J, Sesti G, Schmidt WE, Montanya E, Brett JH et al Liraglutide once a day versus exenatide twice a day for type 2 diabetes: a 26-week randomised, parallel-group, multinational, open-label trial (LEAD-6). Lancet 2009; 374: 39-47.

79 Zinman B, Gerich J, Buse JB, Lewin A, Schwartz S, Raskin P et al. Efficacy and safety of the human glucagon-like peptide-1 analog liraglutide in combination with metformin and thiazolidinedione in patients with type 2 diabetes (LEAD-4 Met + TZD). Diabetes Care 2009; 32: 1224-1230.

80 Bunck MC, Diamant M, Corner A, Eliasson B, Malloy JL, Shaginian RM et al. One-year treatment with exenatide improves beta-cell function, compared with insulin glargine, in metformin-treated type 2 diabetic patients: a randomized, controlled trial. Diabetes Care 2009; 32: 762-768.

81 Buse JB, Garber A, Rosenstock J, Schmidt WE, Brett JH, Videbaek N et al. Liraglutide treatment is associated with a low frequency and magnitude of antibody formation with no apparent impact on glycemic response or increased frequency of adverse events: results from the Liraglutide Effect and Action in Diabetes (LEAD) trials. J Clin Endocrinol Metab 2011; 96: 1695-1702.

82 Pinget M, Goldenberg R, Niemoeller E, Muehlen-Bartmer I, Guo H, Aronson R Efficacy and safety of lixisenatide once daily versus placebo in type 2 diabetes insufficiently controlled on pioglitazone (GetGoal-P). Diabetes Obes Metab 2013; 15: 1000-1007.

83 Riddle MC, Aronson R, Home P, Marre M, Niemoeller E, Miossec P et al. Adding once-daily Lixisenatide for type 2 diabetes inadequately controlled by established basal insulin: a 24-week, randomized, placebo-controlled comparison (GetGoal-L). Diabetes Care 2013; 36: 2489-2496.

84 Vilsboll T, Christensen M, Junker AE, Knop FK, Gluud LL. Effects of glucagon-like peptide-1 receptor agonists on weight loss: systematic review and meta-analyses of randomised controlled trials. BMJ 2012; 344: d7771.

85 Russell-Jones D, Gough S. Recent advances in incretin-based therapies. Clin Endocrinol (Oxf) 2012; 77: 489-499.

86 Waget A, Cabou C, Masseboeuf M, Cattan P, Armanet M, Karaca M et al. Physiological and pharmacological mechanisms through which the DPP-4 inhibitor sitagliptin regulates glycemia in mice. Endocrinology 2011; 152: 3018-3029.

87 Muscelli E, Casolaro A, Gastaldelli A, Mari A, Seghieri G, Astiarraga B et al. Mechanisms for the antihyperglycemic effect of sitagliptin in patients with type 2 diabetes. J Clin Endocrinol Metab 2012; 97: 2818-2826.

88 Younk LM, Mikeladze M, Davis SN. Pramlintide and the treatment of diabetes: a review of the data since its introduction. Expert Opin Pharmacother 2011; 12 1439-1451.

89 Anderson SL, Marrs JC. Dapagliflozin for the treatment of type 2 diabetes. Ann Pharmacother 2012; 46: 590-598.

90 Schouten R, Rijs CS, Bouvy ND, Hameeteman W, Koek GH, Janssen IM et al A multicenter, randomized efficacy study of the endobarrier gastrointestinal liner for presurgical weight loss prior to bariatric surgery. Ann Surg 2010; 251: 236-243.

91 Gersin KS, Rothstein RI, Rosenthal RJ, Stefanidis D, Deal SE, Kuwada TS et al. Open-label, sham-controlled trial of an endoscopic duodenojejunal bypass liner for preoperative weight loss in bariatric surgery candidates. Gastrointest Endosc 2010; 71: 976-982.

92 de Moura EG, Martins BC, Lopes GS, Orso IR, de Oliveira SL, Galvao Neto MP et al. Metabolic improvements in obese type 2 diabetes subjects implanted for 1 year with an endoscopically deployed duodenal-jejunal bypass liner. Diabetes Technol Ther 2012; 14: 183-189.

93 Escalona A, Pimentel F, Sharp A, Becerra P, Slako M, Turiel D et al. Weight loss and metabolic improvement in morbidly obese subjects implanted for 1 year with an endoscopic duodenal-jejunal bypass liner. Ann Surg 2012; 255: 1080-1085. 
94 Cohen RV, Neto MG, Correa JL, Sakai P, Martins B, Schiavon CA et al. A pilot study of the duodenal-jejunal bypass liner in low body mass index type 2 diabetes. $J$ Clin Endocrinol Metab 2013; 98: E279-E282.

95 Mizrahi M, Ben Ya'acov A, llan Y. Gastric stimulation for weight loss. World J Gastroenterol 2012; 18: 2309-2319.

96 Shikora SA, Bergenstal R, Bessler M, Brody F, Foster G, Frank A et al. Implantable gastric stimulation for the treatment of clinically severe obesity: results of the SHAPE trial. Surg Obes Relat Dis 2009; 5: 31-37.

97 Fernandes M, Atallah AN, Soares BG, Humberto S, Guimaraes S, Matos D et al. Intragastric balloon for obesity. Cochrane Database Syst Rev 2007 CD004931.
98 Carlsson LM, Peltonen M, Ahlin S, Anveden A, Bouchard C, Carlsson B et al. Bariatric surgery and prevention of type 2 diabetes in Swedish obese subjects. N Engl J Med 2012; 367: 695-704.

99 Sjostrom L, Lindroos AK, Peltonen M, Torgerson J, Bouchard C, Carlsson B et al. Lifestyle, diabetes, and cardiovascular risk factors 10 years after bariatric surgery. N Engl J Med 2004; 351: 2683-2693.

(i) This work is licensed under a Creative Commons Attribution 3.0 Unported License. To view a copy of this license, visit http:// creativecommons.org/licenses/by/3.0/ 